\title{
QUANTITATIVE DETERMINATION OF THE JUVENILE HORMONES IN THE HAEMOLYMPH OF LOCUSTA MIGRATORIA DURING NORMAL DEVELOPMENT AND AFTER IMPLANTATION OF CORPORA ALLATA
}

\author{
L. Huibregtse-Minderhoud*, M. A. M. Van den Hondel-Franken $\dagger$, A. C. Van der \\ Kerk-Van HoOF*, H. W. A. Biessels*, C. A. Salemink*, D. J. Van der Horst $\dagger$ and A. \\ M. Th. BeENAKKERS ${ }^{\dagger}$ \\ *Laboratory of Organic Chemistry, State University of Utrecht, PO Box 5055, $3502 \mathrm{JB}$ Utrecht, The \\ Netherlands and +Laboratory of Chemical Animal Physiology, State University of Utrecht, 8 \\ Padualaan, 3508 TB Utrecht, The Netherlands
}

(Received 18 June 1979; revised 15 February 1980)

\begin{abstract}
Simultaneous quantitative determination of the three naturally occurring juvenile hormones in insects (JH-I, JH-II and JH-III) was performed on haemolymph samples of both normally developing locusts and locusts implanted with active corpora allata, using capillary gas chromatography with electron capture detection.

In fourth instar female larvae, $24-48 \mathrm{hr}$ after the third ecdysis, as well as in adult females, 18 days after the imaginal ecdysis, only JH-III was detected. In fifth instar female larvae JH-III was present in very low concentrations, if at all.

After implantation of four pairs of corpora allata taken from young fourth instar female larvae or one pair or corpora allata taken from adult females into fifth instar female larvae 0-24 hr after ecdysis, an elevation of the JH-III titre was observed. Neither JH-I nor JH-II could be detected. The amount of JH-III, already elevated $2 \mathrm{hr}$ after implantation, remained high for several days in comparison to that of control insects. On the third day after the subsequent moult the JH-III level was comparable to that of normally developing fifth instar larvae. Factors involved in the achievement of the haemolymph JH-titre are discussed.

Key Word Index. Locusta migratoria, juvenile hormones, capillary gas chromatography, electron capture detection, corpora allata, flight muscles.
\end{abstract}

\section{INTRODUCTION}

IMPLANTATION of active corpora allata (CA) (JoHNSON and HILL, 1975) early in the fifth larval instar of Locusta migratoria results in an increase in heart-beat frequency (Roussel, 1969), a change in pigmentation and a disturbance of metamorphosis (JoLY, 1960; StaAl, 1961; Poels and BeEnakKers, 1969; BEenakKers and VAN DEN BroEK, 1974). Similar effects have also been found upon injection of any of the three naturally occurring insect juvenile hormones (JH's); the activity of JH-I being the most potent (Roussel, 1977). Also, in adult female locusts $\mathrm{JH}$ is involved in maturation of the eggs (Roussel, 1976).

The $\mathrm{JH}$ secreted by the CA reaches its target tissues via the haemolymph, its concentration being controlled by regulatory factors, such as degrading enzymes. In the haemolymph of Locusta a high molecular weight $\mathrm{JH}$-transporting lipoprotein has been identified which is probably capable of protecting the hormone from esterase activity (EMMERICH and HartManN, 1973).

Up till now, JH in the haemolymph of Locusta has only been demonstrated by a Galleria bioassay. In fourth instar female larvae JH-activity appeared to reach a maximum on the first days of the instar, whereas activity was virtually absent in the fifth larval instar. In the adult stage an increasing activity during the gonotrophic cycle was observed (JOHNSON and Hill, 1973a, 1975; Joly et al., 1977). The chemical nature of the actual homologue (or homologues) involved, however, is unknown.

Qualitative and quantitative determination of the threc naturally occurring juvenile hormones at physiological levels in insects by capillary gas chromatography with electron capture detection (GCECD) (HUIBREGTSE-MINDERHOUD, 1979a) now facilitates a definitive analysis of the JH-titre in Locusta.

The present paper is concerned with such an analysis of the JH-titre in the haemolymph of young fourth and fifth instar larvae and of adult females of Locusta. Furthermore, this study focusses on the question which JH homologue(s) is (are) produced in fifth instar larvae upon implantation of active CA and whether the titre fluctuates in the period following implantation. The latter aspect is studied in view of the fact that implantation of CA in young fifth instar larvae influences the development of the flight muscles, normally taking place during the fifth larval instar and early adult stage. Thus, after implantation of CA, Poels and Beenakkers (1969) observed an inhibition of the normal increase in dry weight and protein content of these muscles. This inhibition is accompanied by lower specific activities of enzymes rcpresentative of the main metabolic pathways in the 
flight muscles (VAN DEN Hondel-FranKen et al., 1980 ) and with a delay in invagination of tracheoblasts into the muscle fibres (VAN DEN HONDEL-FrANKEN and BEENAKKERS, unpublished), irrespective of the fact whcther the CA were taken from young fourth instar larvae (larval CA) or from 18 day adult females (adult CA). The nature and the amount of the JH's in the CA-implanted locusts responsible for the retardation of the flight muscle development, however, is as yet unknown.

\section{MATERIALS AND METHODS}

Locusts (Locusta migratoria) were reared under crowded conditions at $30^{\circ} \mathrm{C}, 40 \%$ r.h. and a photoperiod of $12 \mathrm{hr}$ light per day. The insects were fed with reed, supplemented with rolled oats.

Haemolymph $\mathbf{J H}$-titre determinations were carried out in normally developing female locusts, $24-48 \mathrm{hr}$ after the third larval ecdysis, $0-24 \mathrm{hr}$ after the fourth larval ecdysis and 18 days after the imaginal ecdysis, as well as in fifth larval instar females implanted with active CA or injected with a Ringer solution. Implantation experiments were performed as previously described (VAN DEN HONDEL-FRANKEN $e t$ al., 1980). The CA were taken from fourth instar female larvae, $24-48 \mathrm{hr}$ after the third ecdysis, or from female adults, 18 days after the imaginal ecdysis. Fifth instar female larvae (0-24 hr old) were used as recipient insects, receiving four pairs of larval $\mathrm{CA}$ or one pair of adult CA taken up in $25 \mu \mathrm{l}$ of Ringer solution (CA-implanted locusts); controls were injected with $25 \mu$ l of the Ringer solution. The concentrations of the JH's in the haemolymph were determined at different times after treatment.

Samples of haemolymph were taken by a puncture in the ventral membrane between the head and thorax using a Hamilton micro-syringe and kept on ice for at most $10 \mathrm{~min}$. Some crystals of reduced glutathione were added to inhibit tyrosinase activity. Unless otherwise stated haemolymph samples obtained from 10 animals $(0.25-0.70 \mathrm{~g})$ were pooled for each determination. After sampling, the haemolymph was kept frozen until extraction with ether-ethanol (6:1, $\mathrm{v} / \mathrm{v})$ followed by ether extraction. Also, JHdeterminations were performed directly on CA taken from 18 day adult females. After dissection, the CA were sonified for $10 \mathrm{~min}$ at $0^{\circ} \mathrm{C}$ in a Ringer solution to which ether was added and subsequently extracted as described above.

After combining the ether-ethanol and the ether phases, two internal standards were added to the $\mathrm{JH}$ extracts, viz. the 10-trans-isomer of JH-II and the ethylester of the 2Z-isomer of JH-III. After intensive purification of the JH-extract and microderivatization to the 10-heptafluorobutyrate-11methoxy-JH's (HUIBREGTSE-MindERHOUd et al., 1979b) JH-I, JH-II and JH-III were determined simultaneously, using a gas chromatographic system consisting of an all-glass solvent-free solid injector, a set of capillary columns - two liquid phases were used separately-and an electron capture detector. In general, the detection limits for JH-I, JH-II and JH-III were as low as $0.5,0.3$ and $0.2 \mathrm{ng} / \mathrm{sample}$, respectively.

The accuracy of the measurements, defined as the deviation from the true value, was found to be $+2 \%$ at the level of $5 \mathrm{ng} / \mathrm{sample}(n=10)$. The precision, expressed as the standard deviation was $8 \%(n=10)$. These analyses were performed with a $1: 1$ ratio of hormone to internal standard. In separate experiments it was demonstrated that the range between ratios $5: 1$ and 1:4 does not affect the mentioned values. The amount of internal standard was adapted to each individual sample.

\section{RESULTS}

In the haemolymph of normally developing young fourth instar female larvae and of adult females only JH-III was detected (Table 1). Due to an overlapping peak in the gas chromatogram which coincided in part with the peak of JH-III, the presence of JH-III in the fifth larval instar cannot be excluded. The concentration was, however, less than $2.3 \mathrm{ng} / \mathrm{g}$ haemolymph. From 24 to 48 -hr-old fourth instar female larvae haemolymph was sampled until over $1 \mathrm{~g}$ had been collected (about 100 larvae). In these larvae the presence of JH-III could be demonstrated, reaching a level of only $1.1 \mathrm{ng} / \mathrm{g}$ haemolymph. The concentration of JH-III was high in the (reproducing) adult females.

The concentrations of both JH-I and of JH-II in the haemolymph samples from the fourth and fifth instar female larvae and from the adult females were below the detection limits.

Table 2 shows the JH-titres in the haemolymph of

Table 1. JH-titres (ng/g haemolymph) in female locusts of the (a) fourth larval, (b) fifth larval, and (c) adult stage

\begin{tabular}{|c|c|c|c|c|c|c|}
\hline \multicolumn{2}{|c|}{ Age } & \multirow{2}{*}{$\begin{array}{c}\begin{array}{c}\text { Sample } \\
\text { number }\end{array} \\
1\end{array}$} & \multirow{2}{*}{$\begin{array}{c}\begin{array}{c}\text { Weight } \\
\text { (g) }\end{array} \\
1.10\end{array}$} & \multirow{2}{*}{$\begin{array}{r}\text { JH-I * } \\
<0.3\end{array}$} & \multirow{2}{*}{$\frac{\text { JH-II* }}{<0.1}$} & \multirow{2}{*}{$\frac{\text { JH-III }}{0.9}$} \\
\hline (a) & 24-48 hr old fourth instar larvae & & & & & \\
\hline & & 2 & 1.20 & $<0.3$ & $<0.1$ & 1.3 \\
\hline \multirow[t]{2}{*}{ (b) } & $0-24 \mathrm{hr}$ old fifth instar larvae & 1 & 0.30 & $<1.7$ & $<0.6$ & $\leq 1.3$ \\
\hline & & 2 & 0.29 & $<1.8$ & $<1.0$ & $\leq 2.3$ \\
\hline & 18 day adults & 1 & 0.60 & $<1.6$ & $<1.4$ & 44.0 \\
\hline & & 2 & 0.64 & $<1.6$ & $<1.5$ & 36.0 \\
\hline & & 3 & 0.40 & $<2.0$ & $<2.5$ & 38.0 \\
\hline & & 4 & 0.44 & $<1.9$ & $<2.5$ & 74.0 \\
\hline
\end{tabular}

\footnotetext{
* In some cases the detection limits for JH-I and JH-II were higher than 0.5 and 0.3 ng/sample, respectively.
} 
Table 2. JH titres (ng/g haemolymph) in female locusts determined $24 \mathrm{hr}$ after (a) implantation of larval CA, and (b) injection of Ringer solution

\begin{tabular}{lcccc}
\hline Experiment & $\begin{array}{c}\text { Serial } \\
\text { number* }\end{array}$ & JH-I $\dagger$ & JH-II $\dagger$ & JH-III \\
\hdashline (a) Four pairs of & a 1 & b.d. & b.d. & 15.0 \\
larval CA & a2 & b.d. & b.d. & 16.0 \\
(b) Ringer solution & b1 & b.d. & b.d. & $\leq 2.2$ \\
& b2 & b.d. & b.d. & 1.7 \\
\hline
\end{tabular}

* bl and b2 are the determinations of the controls belonging to $a 1$ and $a 2$, respectively.

$\dagger$ b.d.: value below detection limit; JH-1: less than 0.8-1.5 $\mathrm{ng} / \mathrm{g}$ haemolymph; JH-II: less than $0.5-0.9 \mathrm{ng} / \mathrm{g}$ haemolymph.

Each value is obtained from one group of 10 animals.

fifth instar female larvae, $24 \mathrm{hr}$ after implantation of CA taken from 24 to 48 -hr-old fourth instar larvae. JH-I and JH-II were below the detection limits (less than $0.8-1.5 \mathrm{ng} / \mathrm{g}$ and $0.5-0.9 \mathrm{ng} / \mathrm{g}$ haemolymph, respectively). The JH-III titre was strongly elevated as compared with the control insects. This is most interesting, since the level of JH-III in the haemolymph of the donor insects appeared to be very low (approx. $1.1 \mathrm{ng} / \mathrm{g}$ haemolymph; Table 1).

The JH-titres, determined in the haemolymph of fifth instar female larvae at different times in the period following implantation of CA taken from 18 day adult females are presented in Table 3.

JH-I and JH-II were again below the detection limits (less than $0.7-2.4 \mathrm{ng} / \mathrm{g}$ and $0.4-1.4 \mathrm{ng} / \mathrm{g}$ haemolymph, respectively), whereas within $2 \mathrm{hr}$ after implantation of adult $\mathrm{CA}$ a considerable elevation of the JH-III titre was observed. Since the CA contained only $0.3 \mathrm{ng} \mathrm{JH}-\mathrm{III} /$ pair (Table 4), obviously the JH-III is not stored within the CA. It seems clear that a high titre was maintained for at least 3 days after implantation. On the fifth day the concentration was reduced. On the third day after the subsequent moult the JH-III titre was further reduced to the level of 3.0 ng/g haemolymph.

In the control insects the JH-III level was very low, except in one group of locusts 24 hr after injection of Ringer solution in which a titre of $8.5 \mathrm{ng} \mathrm{JH}-\mathrm{III} / \mathrm{g}$ haemolymph was found; for this exception no explanation can be given.

\section{DISCUSSION}

At any moment in an insect's development the JHtitre in the haemolymph is the balance between synthesis and release of $\mathrm{JH}$ by the $\mathrm{CA}$, its enzymic degradation and its protection by JH-carriers (AKamatsu et al., 1975). The activity of the CA is regulated by cerebral nervous and/or neurosecretory centres as well as by blood-borne factors such as

* Using radioimmunoassay, BAEHR et al. (1979) recently identified the presence of JH-I immunoreactive substances in the haemolymph of Locusta during the last larval instar, with a maximum concentration during the first hours after the fourth ecdysis. substrate precursors of $\mathbf{J H}$, other specific hormones and neurosecretions (WILLIAMS, 1976).

In the haemolymph of 18 day adult females of Locusta only JH-III was detected definitively, which is in agreement with the in vivo findings in reproducing adults of Schistocerca gregaria (TRAUTMANN et al., 1974; BLIGHT and WeNHAM, 1976) and observations on in vitro incubation experiments with CA from Schistocerca vaga (JuDY et al., 1973). CA from Schistocerca gregaria produce in vitro both $\mathrm{JH}-\mathrm{I}$ and JH-III (PratT and ToBE, 1974). JH-synthesis in in vitro incubations, however, might differ significantly from the in vivo synthetic activity of CA (PRATT et al., 1976). Also the haemolymph of young fourth instar female larvae contains detectable amounts of JH-III, which is in agreement with the findings in Schistocerca gregaria (Blight and Wenham, 1976). These results indicate that in Locusta JH-III has both morphogenetic and gonadotrophic functions, although as demonstrated with exogenous $\mathrm{JH}$ the biological activities of $\mathrm{JH}-\mathrm{I}$ and $\mathrm{JH}$-II surpass that of JH-III (Roussel, 1977). In young fifth instar female larvae JH-III, if at all, is present in very low concentrations. ${ }^{*}$ This may clarify the bioassay results of JOHNSON and HILL (1973a). However, in experiments in which $\mathrm{CA}$ from fifth instar larvae were implanted into Galleria they observed that the CA were capable of releasing $\mathrm{JH}$. A conceivable explanation for this phenomenon might be that isolated CA do not behave in the same way as those connected with the brain complex. On the other hand, it is also possible that in the fifth larval instar of Locusta $\mathrm{JH}$-specific esterases play an important role in lowering of the hormone titre by hydrolysis of tree as well as protein bound $\mathrm{JH}$, as demonstrated for Manduca sexta (SANBURG et al., 1975a). The latter possibility seems to be ruled out by the results of our implantation experiments. After implantation of active $\mathrm{CA}$ in fifth instar larvae the $\mathrm{JH}$-titre is strongly elevated, indicating that there is no substantial inactivation of the hormone.

The elevated JH-III titres in the haemolymph of the CA-implanted locusts clearly show that the implanted CA synthesize and release JH-III since the isolated CA of adult female locusts contain only small amounts of JH-III; the presence of any JH within the CA confirms the bioassay results of JoHNSON and HiLL (1973b). The JH-III titre, already raised $2 \mathrm{hr}$ after implantation, remained high for several days. Apparently, the implanted CA were capable of prolonged activity which may be explained by the presence of an activating factor in the haemolymph of the fifth instar larvae. On the other hand, this might also imply that the virtual absence of $\mathrm{JH}$ in the haemolymph of normally developing fifth instar larvae is caused by an inhibition of secretion by the CA by way of nervous means. Regulation of CA-activity by nervous inhibition and humoral stimulation has already been suggested in adult females of Diploptera punctata (STAY and TOBE, 1977) and in larval and adult Locusta (Joly, 1967; Moulins et al., 1974). Although determination of JH-titres in the haemolymph samples by GC-ECD reflects both free and lipoprotein bound $\mathrm{JH}$, the relative high $\mathrm{JH}$-titre suggests that $\mathrm{JH}$ transporting carriers in the haemolymph of the CAimplanted locusts are involved in protecting the $\mathrm{JH}$ 


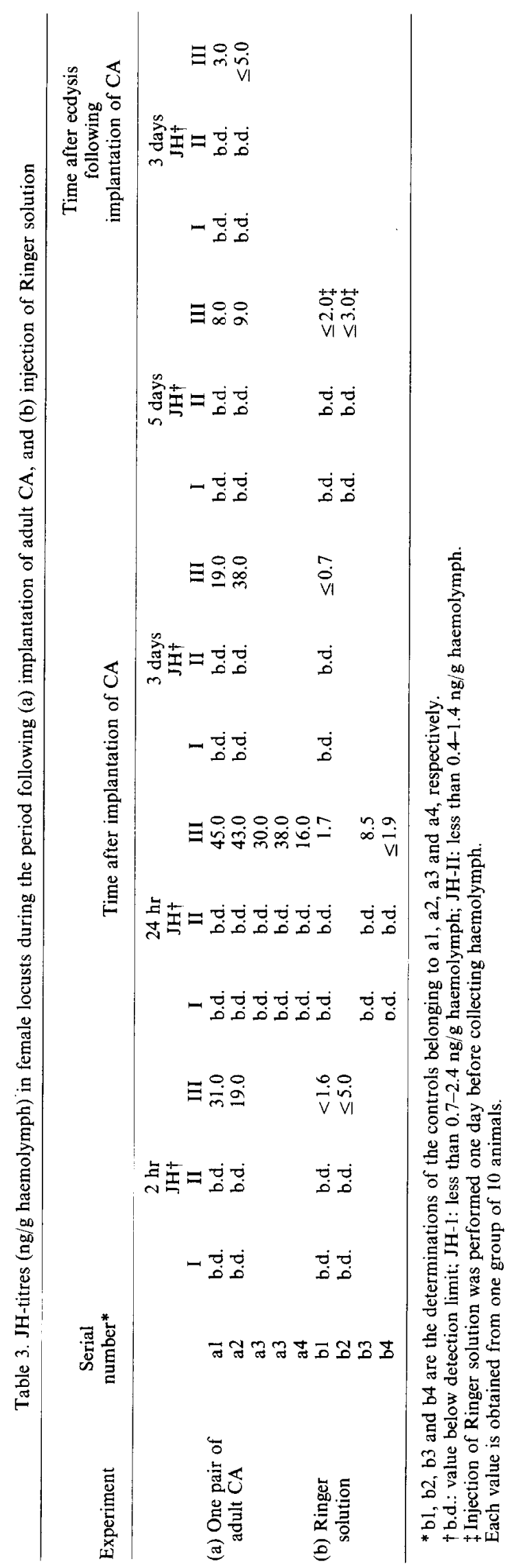


Table 4. JH-concentrations (ng) within CA taken from adult females

\begin{tabular}{lcccc}
\hline Sample & Number & JH-I & JH-II & JH-III \\
\hline $\begin{array}{l}\text { CA taken from 18 } \\
\text { day adult females }\end{array}$ & 7 pairs & $<0.5$ & $<0.3$ & 2.3 \\
\hline
\end{tabular}

from esterase activity. Results of studies on larval haemolymph lipoproteins that are in progress suggest an induction of $\mathrm{JH}$-transporting lipoprotein synthesis after implantating active CA in fifth instar larvae (VAN DER HORST et al., unpublished). Although it is not clear whether the JH-binding protein carrier exerts a synergistic action with JH at target tissues (SANBURG et al., 1975b) or not (FERKOVICH et al., 1976) the implantation of larval CA as well as of adult CA inhibits normal development, including developmental processes in the flight muscles (VAN DEN HoNDEL-FranKen et al., 1980).

\section{REFERENCES}

Akamatsu Y., Dunn P. E., Kezdy F. J., Kramer K. J., LaW J. H., Reibstein D. and SANBurg L. L. (1975) Biochemical aspects of juvenile hormone action in insects. In Control Mechanisms and Development (Ed. by MEINTS R. and Davies E.) pp. 123-149. Plcnum Press, New York.

Baehr J.-C., Porcheron P., Papillon M. and Dray F. (1979) Haemolymph levels of juvenile hormone, ecdysteroids and protein during the last two larval instars of Locusta migratoria. J. Insect Physiol. 25, 415-421.

Beenakkers A. M. Th. and VAN Den Broek A. TH. M. (1974) Influence of juvenile hormone on growth and digestion in fifth instar larvae and adults of Locusta migratoria. $J$. Insect Physiol. 20, 1131-1142.

BLIGHT M. and WfNhAM M. J. (1976) Identification of JH-III in haemolymph from adults and larvae of Schistocerca gregaria. Insect Biochem. 6, 35-38.

EMMERICH H. and HARTMANN R. (1973) A carrier lipoprotein for juvenile hormone in the haemolymph of Locusta migratoria. J. Insect Physiol. 19, 1663-1675.

Ferkovich S. M., Silhacex D. L. and Rutter R. R. (1976) The binding of juvenile hormone to larval epidermis: influence of a carrier protein from the hemolymph of Plodia interpunctella. In The Juvenile Hormones. (Ed. by Gilbert L. I.) pp. 342-353. Plenum Press, New York.

HUIBREGTSE-MiNDERHOUd L. (1979a) Simultane kwantitatieve bepaling van de juveniel hormonen I, II en III in insekten. Chapter 4, Ph.D. Thesis, Utrecht.

HuibregtSe-Minderhoud L., VAN DER KerK-VAN HoOF A C., Wijkens P., Biessels H. W. A. and Salemink C. A. (1979b) A method for the quantitative determination of juvenile hormones in insects. Recl Trav. chim. Pays-Bas 98, 421-422.

JoHNSON R. A. and Hill L. (1973a) The activity of the corpora allata in the fourth and fifth larval instars of the migratory locust. J. Insect Physiol. 19, 1921-1932.

Johnson R. A. and Hill L. (1973b) Quantitative studies on the activity of the corpora allata in adult male Locusta and Schistocerca. J. Insect Physiol. 19, 2459-2467.

JoHnson R. A. and HiLl. L. (1975) Activity of the corpora allata in the adult female migratory locust. $J$. Insect Physiol. 21, 1517-1519.

Joly L. (1960). Fonctions des corpora allata chez Locusta migratoria L. Ph.D. Thesis, Strasbourg.

Joly L., HoffmanN J. and Joty P. (1977) Controle humoral de la différenciation phasaire chez Locusta migratoria migratoroides (R. \&. F.) (Orthoptères). Acrida VI, 33-42.

Joly P. (1967) Comparaison du volume et de l'activité physiologique des corpora allata de Locusta migratoria $\mathrm{L}$. Ann. Soc. ent. Fr. 3, 601-608.

Judy K., Schooley D., Hall M. S., Bergot B. J. and SidDall J. B. (1973) Chemical structure and absolute configuration of a juvenile hormone from grasshopper corpora allata in vitro. Life Sci. 13, 1511-1516.

Moulins M., Girardie A. and Girardie J. (1974) Manipulation of sexual physiology by brain stimulation in insects. Nature, Lond. 250, 339-340.

Poels C. L. M. and Beenakkers A. M. Th. (1969) The effects of corpus allatum implantation on the development of flight muscles and fat body in Locusta migratoria. Ent. exp. appl. 12, 312-324.

Pratt G. E. and Tobe S. S. (1974) Juvenile hormones radiobiosynthesized by corpora allata of adult female locusts in vitro. Life Sci. 14, 575-586.

Pratt G. E., Weaver R. J. and Hamnett A. F. (1976) Continuous monitoring of juvenile hormone release by superfused corpora allata of Periplaneta americana. In The Juvenile Hormones (Ed. by GILBERT L. I.) pp. 164-178. Plenum Press, New York.

Roussel J.-P. (1969) Action de l'ablation et de l'implantation de corpora allata sur le rythme cardiaque de Locusta migratoria L. C.R. Acad. Sci., Paris (D) 269, 371-373.

Rousser J.-P. (1976) Comparaison de l'activité des hormones juvéniles en $\mathrm{C}_{18}$ (JH-I) et en $\mathrm{C}_{16}$ (JH-III) sur la fonction gonadotrope de Locusta migratoria. C.R. Acad. Sci., Paris (D) 283, 947-949.

Roussel J.-P. (1977) L'action différentielle des hormones juvéniles sur la métamorphose chez Locusta migratoria. $J$. Insect Physiol. 23, 1143-1150.

Sanburg L. L., Kramer K. J., Kezdy F. J. and Law J. H. (1975a) Juvenile hormone-specific esterases in the haemolymph of the tobacco hornworm Manduca sexta. $J$. Insect Physiol. 21, 873-887.

Sanburg L. L., Kramer K. J., Kezdy F. J., Law J. H. and Oberlander H. (1975b) Role of juvenile hormone esterases and carrier proteins in insect development. Nature, Lond. 253, 266-267.

StaAl G. B. (1961) Studies on the physiology of phase induction of Locusta migratoria migratorioides R. \&. F. Ph.D. Thesis, Wageningen.

STAY B. and TOBE S. S. (1977) Control of juvenile hormone biosynthesis during the reproductive cycle of a viviparous cockroach. - - I. Activation and inhibition of corpora allata. Gen. comp. Endocr. 33, 531-540.

Trautmann K. H., Masner P., Schuler A., Suchy M. and WIPF H.-K. (1974) Evidence of the juvenile hormone methyl (2E, 6E)-10,11-epoxy-3,7,11-trimethyl-2,6dodecadienoate $(\mathrm{JH}-3)$ in insects of four orders. $Z$. Naturforsch. 29c, 757-759.

Van den Hondel-Franken M. A. M., Van den Broek A. TH. M. and BeEnaKkers A. M. Th. (1980) Flight muscle development in Locusta migratoria: effects of implantation of corpora allata on the attainment of metabolic enzyme activities. Gen. comp. Endocr. $\mathbf{4 1}$, in press.

Williams C. M. (1976) Juvenile hormone ... in retrospect and in prospect. In The Juvenile Hormones (Ed. by GILBERT L. I.) pp. 1-14. Plenum Press, New York. 